\title{
Gymnasium-Based Unsupervised Exercise Maintains Benefits in Oxygen Uptake Kinetics Obtained Following Supervised Training in Type 2 Diabetes
}

\author{
Oscar Mac Ananey \\ Technological University Dublin, oscar.macananey@tudublin.ie \\ D O'Shea \\ Loughlinstown Hospital \\ S Warmington \\ Trinity College Dublin
}

See next page for additional authors

Follow this and additional works at: https://arrow.tudublin.ie/scschbioart

Part of the Exercise Physiology Commons

\section{Recommended Citation \\ Mac Ananey, O. (2012) Gymnasium-based unsupervised exercise maintains benefits in oxygen uptake kinetics obtained following supervised training in type 2 diabetes. Applied Physiology, Nutrition and Metabolism, 2012 Aug;37(4):599-609. doi: 10.1139/h2012-012. Epub 2012 May 7.}

This Article is brought to you for free and open access by the School of Biological Sciences at ARROW@TU Dublin. It has been accepted for inclusion in Articles by an authorized administrator of ARROW@TU Dublin. For more information, please contact arrow.admin@tudublin.ie, aisling.coyne@tudublin.ie,gerard.connolly@tudublin.ie.

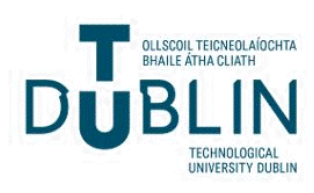


Authors

Oscar Mac Ananey, D O'Shea, S Warmington, S Green, and M Egana

This article is available at ARROW@TU Dublin: https://arrow.tudublin.ie/scschbioart/134 


\title{
Gymnasium-based unsupervised exercise maintains benefits in oxygen uptake kinetics obtained following supervised training in type 2 diabetes
}

\author{
Oscar MacAnaney, Donal O'Shea, Stuart A. Warmington, Simon Green, and \\ Mikel Egaña
}

\begin{abstract}
Supervised exercise (SE) in patients with type 2 diabetes improves oxygen uptake kinetics at the onset of exercise. Maintenance of these improvements, however, has not been examined when supervision is removed. We explored if potential improvements in oxygen uptake kinetics following a 12-week SE that combined aerobic and resistance training were maintained after a subsequent 12-week unsupervised exercise (UE). The involvement of cardiac output (CO) in these improvements was also tested. Nineteen volunteers with type 2 diabetes were recruited. Oxygen uptake kinetics and $\mathrm{CO}$ (inert gas rebreathing) responses to constant-load cycling at $50 \%$ ventilatory threshold $\left(V_{\mathrm{T}}\right), 80 \% V_{\mathrm{T}}$, and mid-point between $V_{\mathrm{T}}$ and peak workload $(50 \% \Delta)$ were examined at baseline (on 2 occasions) and following each 12-week training period. Participants decided to exercise at a local gymnasium during the UE. Thirteen subjects completed all the interventions. The time constant of phase 2 of oxygen uptake was significantly faster $(p<0.05)$ post-SE and post-UE compared with baseline at $50 \% V_{\mathrm{T}}(17.3 \pm 10.7 \mathrm{~s}$ and $17.5 \pm 5.9 \mathrm{~s}$ vs. $29.9 \pm 10.7 \mathrm{~s}), 80 \% V_{\mathrm{T}}(18.9 \pm 4.7$ and $20.9 \pm 8.4$ vs. $34.3 \pm 12.7 \mathrm{~s})$, and $50 \% \Delta(20.4 \pm 8.2 \mathrm{~s}$ and $20.2 \pm 6.0 \mathrm{~s}$ vs. $27.6 \pm 3.7 \mathrm{~s})$. SE also induced faster heart rate kinetics at all 3 intensities and a larger increase in $\mathrm{CO}$ at $30 \mathrm{~s}$ in relation to $240 \mathrm{~s}$ at $80 \% \mathrm{~V}_{\mathrm{T}}$; and these responses were maintained post-UE. Unsupervised exercise maintained benefits in oxygen uptake kinetics obtained during a supervised exercise in subjects with diabetes, and these benefits were associated with a faster dynamic response of heart rate after training.
\end{abstract}

Key words: cardiac output, gymnasium-based, home-based, cycling, type 2 diabetes, resistance, aerobic.

Résumé : Des exercices physiques supervisés (SE) chez des diabétiques de type 2 améliorent la cinétique de la consommation d'oxygène au début de l'exercice. Néanmoins, on ne sait pas si ces améliorations sont maintenues lorsque cesse la supervision. On explore si les améliorations de la cinétique du consommation d'oxygène suscitées par 12 semaines d'entraînement aérobie et contre résistance sont maintenues au cours des 12 semaines suivantes sans supervision (UE). On vérifie en outre l'implication du débit cardiaque $(\mathrm{CO})$ dans ces améliorations. On sollicite 19 volontaires présentant un diabète de type 2 . On analyse la cinétique du consommation d'oxygène et du $\mathrm{CO}$ (réinspiration d'un gaz inerte) au cours d'un exercice sur vélo aux intensités suivantes : $50 \%$ du seuil ventilatoire $\left(V_{\mathrm{T}}\right), 80 \%$ du $V_{\mathrm{T}}$ et à mi-chemin entre le $V_{\mathrm{T}}$ et le pic de travail $(50 \% \Delta)$, et ce, au début (en deux occasions) et après chaque programme de 12 semaines d'entraînement. Les participants décident de s'entraîner au gymnase local en période UE. Treize sujets se rendent jusqu'à la fin. La constante de temps de la phase 2 du consommation d'oxygène est significativement plus petite $(p<0,05)$ post-SE et post-UE comparativement au départ à $50 \% V_{\mathrm{T}}(17,3 \pm 10,7$ et $17,5 \pm 5,9$ vs. $29,9 \pm 10,7 \mathrm{~s}), 80 \%$ VT $(18,9 \pm 4,7$ et $20,9 \pm 8,4$ vs. $34,3 \pm$ $12,7 \mathrm{~s})$ et $50 \% \Delta(20,4 \pm 8,2$ et $20,2 \pm 6,0$ vs. $27,6 \pm 3,7 \mathrm{~s})$. SE améliore la cinétique du rythme cardiaque (HR) aux trois intensités et suscite une plus grande augmentation du $\mathrm{CO}$ à la $30^{\mathrm{e}}$ seconde comparativement à la $240^{\mathrm{e}}$ seconde à $80 \% V_{\mathrm{T}}$; ces ajustements sont maintenus post-UE. Le programme non supervisé d'exercices maintient les gains observés sur le plan de la cinétique du consommation d'oxygène au cours du programme supervisé d'exercices chez des diabétiques; ces gains sont associés à une réponse dynamique plus rapide du HR à la suite du programme d'entraînement.

Mots-clés : débit cardiaque, exercice en gymnase, exercice à domicile, vélo, diabète de type 2 , résistance, aérobie.

[Traduit par la Rédaction]

Received 29 June 2011. Accepted 10 January 2012. Published at www.nrcresearchpress.com/apnm on 7 May 2012.

O. MacAnaney and M. Egaña. Department of Physiology, Trinity Biomedical Sciences Institute, Trinity College Dublin, Dublin 2, Ireland.

D. O'Shea. Endocrinology, St Columcilles and St Vincent's Hospitals Co. Dublin, Ireland.

S.A. Warmington. Centre for Physical Activity and Nutrition Research, School of Exercise and Nutrition Sciences, Deakin University, Victoria, Australia.

S. Green. School of Science and Health, University of Western Sydney, NSW, Australia.

Corresponding author: Mikel Egaña (e-mail: megana@tcd.ie). 


\section{Introduction}

The rate at which pulmonary oxygen uptake increases during the initial period of exercise ( $\dot{V} \mathrm{O}_{2}$ kinetics) is slower in young and middle-aged subjects with type 2 diabetes compared with nondiabetic controls (Regensteiner et al. 1998; Brandenburg et al. 1999; Bauer et al. 2007; MacAnaney et al. 2011a), although recent data suggests that $\dot{V} \mathrm{O}_{2}$ kinetics are not impaired in older men with type 2 diabetes compared with aged-matched healthy controls (Wilkerson et al. 2011). There is some debate as to whether the source of the slower $\dot{V} \mathrm{O}_{2}$ kinetic responses observed in young and middle-aged diabetics is due to reduced $\mathrm{O}_{2}$ delivery and (or) due to lower levels of $\mathrm{O}_{2}$ extraction. In healthy individuals during cycling exercise it appears that $\dot{V} \mathrm{O}_{2}$ kinetics are limited by the oxidative machinery rather than $\mathrm{O}_{2}$ delivery per se (reviewed by Poole et al. (2008)). However, in type 2 diabetes $\dot{V} \mathrm{O}_{2} \mathrm{ki}-$ netics are impaired, at least in part, due to a reduced $\mathrm{O}_{2}$ delivery to the contracting muscles. Support for reduced $\mathrm{O}_{2}$ delivery as the source of the impairment can be found in the fact that in the rat spinotrapezius muscle capillary haemodynamics are reduced at rest (Padilla et al. 2006), and when this muscle is electrically stimulated the microvascular partial pressure of oxygen response is also impaired in diabetics compared with nondiabetics (Padilla et al. 2007). Similarly, in humans with type 2 diabetes the microvascular blood flow responses, estimated from simultaneously measured near-infrared spectroscopy-derived concentration of deoxygenated haemoglobin of the thigh and pulmonary $\dot{V} \mathrm{O}_{2}$ responses, were significantly slower during moderate cycling compared with healthy controls (Bauer et al. 2007), suggesting, together with the findings by Padilla et al. (2007), a limitation in oxygen transport relative to oxygen usage in diabetes. In addition, we have recently shown that the dynamic response of vascular conductance in the contracting calf muscle is slowed in females with type 2 diabetes (MacAnaney et al. 2011b), and others reported reduced steadystate measurements of leg blood flow during cycling (Kingwell et al. 2003; Lalande et al. 2008) in diabetic humans. However, the role of the skeletal muscle in the impaired submaximal exercise responses observed in type 2 diabetes cannot be excluded given the evidence of a lower mitochondrial content (Ritov et al. 2005) and abnormal mitochondrial function (Kelley et al. 2002; Ritov et al. 2005).

Regardless of the mechanism, the slowing of the $\dot{V} \mathrm{O}_{2} \mathrm{ki}$ netic response is associated with a greater reliance on anaerobic metabolism (Timmons et al. 1996), more rapid fatigue, and a lower exercise tolerance (Hughson and Tschakovsky 1999). This might help explain the lower exercise tolerance in individuals with type 2 diabetes (Kjaer et al. 1990; Regensteiner et al. 1995, 1998, 2009; Baldi et al. 2003. MacAnaney et al. 2011a) and their perception that routine daily activities are more difficult to perform when compared with healthy controls (Huebschmann et al. 2009). Therefore, interventions aimed at accelerating the $\dot{V} \mathrm{O}_{2}$ kinetic response might be important to improve exercise tolerance in diabetic individuals and reduce the associated risk of mortality (Wei et al. 2000).

Short-term, supervised exercise training accelerates the kinetic response of $\dot{V} \mathrm{O}_{2}$ during submaximal exercise (Brandenburg et al. 1999) and increases exercise tolerance in type 2 diabetes (reviewed by Zanuso et al. (2010)). At present the physiological mechanisms underlying these exercise adaptations are not known, although they might include mechanisms that enhance $\mathrm{O}_{2}$ delivery to (i.e., cardiac output, muscle blood flow) — and (or) $\mathrm{O}_{2}$-dependent metabolism within - contracting myocytes. In addition, relatively little is known about the period over which these short-term improvements are maintained after supervision has been removed. An important objective of exercise training is to help individuals create and maintain their own self-controlled programme of physical activity once the supervision has ceased. However, home-based unsupervised exercise has been shown insufficient to maintain benefits in glycaemic control and body composition obtained following a supervised exercise mainly because of reductions in exercise adherence in type 2 diabetes (Dunstan et al. 2005). To our knowledge, the effectiveness of such a programme in maintaining improvements in $\dot{V} \mathrm{O}_{2}$ kinetics and exercise tolerance is not known.

To explore the mechanistic basis of the training-induced improvement in $\dot{V} \mathrm{O}_{2}$ kinetics, the present study tested the hypothesis that supervised exercise training increases the rate of adjustment of heart rate, cardiac output $(\mathrm{CO})$, and $\dot{V} \mathrm{O}_{2}$ during submaximal exercise. Whether or not such improvements could be maintained with a subsequent period (12 weeks) of unsupervised training was also tested.

\section{Materials and methods}

\section{Subjects}

Nineteen volunteers (12 men and 7 women) with type 2 diabetes (mean $\pm \mathrm{SD}$; age, $50 \pm 6$ years; $\mathrm{HbA}_{1 \mathrm{c}}, 7.3 \% \pm$ $1.2 \%$; fasting glucose, $8.4 \pm 1.7 \mathrm{mmol} \cdot \mathrm{L}^{-1}$ ) were recruited from the Diabetes Unit at St Columcille's Hospital, Dublin, Ireland. Participants were excluded if diagnosed with peripheral arterial disease, hypertension, coronary heart disease, neuropathy, or retinopathy, or had smoked during the 12 months preceding the study. Subjects were taking metformin $(n=7)$ or thiazolidinedione $(n=1)$ mono-therapy or were undergoing dietary control $(n=11)$ of their diabetes. All subjects had a clinical history of diabetes ranging between 1 and 4 years, but immediately prior to the study did not have clinical evidence of ischaemic heart disease (normal electrocardiogram during treadmill stress test), kidney dysfunction (consistent urinary protein $<200 \mathrm{mg} \cdot \mathrm{dL}^{-1}$ ), or liver dysfunction (urinary creatinine levels $<2.2 \mathrm{mg} \cdot \mathrm{dL}^{-1}$ ).

Female participants were both premenopausal $(n=3)$ and postmenopausal $(n=4)$. Subjects were classified as inactive $\left(<1 \mathrm{~h} \cdot\right.$ week $^{-1}$ of moderate intensity exercise in the preceding 3 months), which was confirmed using the Low Level Physical Activity Recall (LOPAR) questionnaire (Kriska et al. 2006). All subjects provided written informed consent prior to participation, and the study was approved by the Faculty of Health Science Research Ethics Committee, Trinity College Dublin, and conducted in accordance with the Declaration of Helsinki.

\section{Overview of experimental protocol}

Subjects were requested to participate in a 12-week supervised exercise training programme (SE) immediately followed by a 12-week unsupervised exercise training programme (UE). Baseline laboratory testing occurred twice (BS1 and 
BS2) separated by 12 weeks. This control period aimed to examine stability of measurements prior to entering the training programme, during which subjects did not perform any regular physical exercise apart from their customary recreational physical activities (i.e., walking). Laboratory testing was then repeated post-SE and post-UE.

\section{Subject attrition}

All 19 subjects completed laboratory testing at BS1. Of these, 15 completed laboratory testing at BS2. All 19 participants entered the 12-week SE, during which 4 were withdrawn from the study because of poor adherence to the exercise training. As such, 15 subjects entered the 12-week UE. Early in the UE an additional 2 subjects withdrew from the study for personal reasons, and so 13 subjects completed the laboratory testing post-UE.

The analysis for the control phase (BS1 vs. BS2) included data from 15 subjects (10 men, 5 women; 2 postmenopausal). The analysis for the exercise intervention phase (baseline vs. post-SE vs. post-UE) included responses from the 13 participants ( 8 men, 5 women; 3 postmenopausal) that completed the 2 training phases. For the training related effects, "baseline" data were calculated as the average of BS1 and BS2 when the physiological responses were not significantly different between the 2 baselines (the majority of the cases, see Results section) as this approach would yield a value closer to the true baseline value. Instead, BS2 measurements were used when a significant difference between the 2 baselines was observed and for subjects' physical characteristics. BS1 data were used for subjects that entered the training program without completing laboratory testing at $\mathrm{BS} 2(n=2)$.

\section{Laboratory testing}

All laboratory testing utilised identical protocols to those described previously (MacAnaney et al. 2011a). At each laboratory testing phase (BS1, BS2, post-SE, post-UE) subjects attended the human laboratory of the Department of Physiology, Trinity College Dublin, for 3 visits over 8 days. For premenopausal subjects this was aligned with the mid-follicular phase of the menstrual cycle (days 5-12). Each visit was separated by $36-72 \mathrm{~h}$. Before each visit subjects were asked to refrain from consuming caffeine and alcohol in the $24 \mathrm{~h}$ prior to testing, in addition to limiting exercise to activities of daily living. All exercise for the laboratory testing was performed on an electrically braked cycle ergometer (Excalibur Sport, Lode, Groningen, Netherlands).

During visit 1 , subjects performed a graded cycling exercise test to failure to determine the ventilatory threshold $\left(V_{\mathrm{T}}\right)$ and peak $\dot{V} \mathrm{O}_{2}$. Following 3 min of rest, subjects cycled at an initial workload of $40 \mathrm{~W}$, which was increased by $20 \mathrm{~W}$ every 3 min until the required cadence (60 repetitions per minute) could not be maintained (i.e., task failure). The peak workload achieved was defined as the highest workload able to be maintained for at least $1 \mathrm{~min}$. From this test, the workload at which the $V_{\mathrm{T}}$ occurred was determined using the V-slope method (Beaver et al. 1986; Amann et al. 2004).

On each remaining testing day (2 and 3 ), subjects were required to complete exercise bouts at 3 different workloads, $50 \% V_{\mathrm{T}}, 80 \% V_{\mathrm{T}}$, and $50 \% \Delta$ (midpoint between $V_{\mathrm{T}}$ and peak workload) according to the following sequence: $3 \mathrm{~min}$ rest, 7 min cycling $\left(50 \% V_{\mathrm{T}}\right), 10 \mathrm{~min}$ rest, 7 min cycling $\left(80 \% V_{\mathrm{T}}\right), 15 \mathrm{~min}$ rest, $7 \mathrm{~min}$ cycling $(50 \% \Delta)$. Subjects then rested for $45 \mathrm{~min}$ before repeating the exercise sequence. Previous data suggest that the rest periods used were sufficient for heart rate (HR) and blood lactate to return to resting levels (Barstow et al. 1996; Burnley et al. 2006). The first three 7-min bouts at each intensity were used to determine $\dot{V} \mathrm{O}_{2}$ and $\mathrm{HR}$ kinetics, and the fourth bout at each intensity was used for determination of $\mathrm{CO}$ responses. Exercise intensities at BS1, BS2, post-SE, and post-UE were all calculated from the graded cycling test performed at BS1 (i.e., exercise workloads were not recalculated).

\section{Measurements}

Throughout rest and during exercise HR was recorded every 5 s (S725x, Polar Electro Oy, Kempele, Finland). In addition, subjects wore a facemask to collect expired air and determine $\dot{V} \mathrm{O}_{2}$ on a breath-by-breath basis using an online metabolic system (Innocor, Innovision A/S, Odense, Denmark). This system was also used to measure $\mathrm{CO}$ during the final 7 min of exercise at each intensity on testing day 3 , but at 2 time-points only ( $30 \mathrm{~s}$ and $240 \mathrm{~s}$ ). CO was measured using an inert gas rebreathing technique as previously used during similar exercise testing procedures (Jakovljevic et al. 2008; MacAnaney et al. 2011a). Stroke volume was calculated as $\mathrm{CO} / \mathrm{HR}$. The rate of increase of $\mathrm{CO}$ relative to its steady-state level was estimated by (CO at 30s - resting $\mathrm{CO}) /(\mathrm{CO}$ at $240 \mathrm{~s}$ - resting $\mathrm{CO}) \cdot 100$.

\section{Data analysis}

To determine the kinetic parameters of $\dot{V} \mathrm{O}_{2}$ for each subject, at each exercise intensity, the 7-min data sets were analysed according to previously published methods (MacAnaney et al. 2011a). Briefly, data sets were linearly interpolated to provide values at 1 -s intervals, then time aligned and averaged. Data were then smoothed using a 5-s moving average filter. Kinetic parameters at each intensity were determined by fitting a multiphasic exponential curve to the results (see eq. [1] below). For exercise at $50 \% V_{\mathrm{T}}$ and $80 \%$ $V_{\mathrm{T}}$ a biphasic exponential curve model was used (i.e., utilizing only the first 2 exponential component terms in eq. [1]), while for the $50 \% \Delta$, the full triphasic function was used.

$$
\begin{aligned}
& {[1] \quad \dot{V} \mathrm{O}_{2}(t)=\text { baseline } \dot{V} \mathrm{O}_{2}+A_{1}\left[1-e^{-\left(t-T D_{1}\right) / \tau_{1}}\right] U_{1}} \\
& +A_{2}\left[1-e^{-\left(t-T D_{2}\right) / \tau_{2}}\right] U_{2}+A_{3}\left[1-e^{-\left(t-T D_{3}\right) / \tau_{3}}\right] U_{3}
\end{aligned}
$$

The 3 exponential terms represent the "cardiodynamic", "fast", and "slow" components of the $\dot{V} \mathrm{O}_{2}$ response to exercise. Baseline $\dot{V} \mathrm{O}_{2}$ represents oxygen uptake during the initial 3-min rest period of each exercise sequence; and for each exponential term $A$ is the amplitude; $\tau$ is the time constant; and TD is the time delay. The parameter $U$ is a conditional expression that limits the fitting of a particular phase to the period at and beyond the time delay associated with that phase. The models were fitted using a weighted least-squares nonlinear regression procedure (TableCurve 2D, Systat, USA).

The mean response time (MRT) represents the time to reach $\sim 63 \%$ of the difference between baseline and the exercise plateau (MacDonald et al. 1998) and was calculated as a weighted sum of the time delay and time constant of each 
phase according to eq. [2] (using the first 2 components for $50 \% V_{\mathrm{T}}$ and $80 \% V_{\mathrm{T}}$ and all 3 components for $50 \% \Delta$ ):

$$
\begin{aligned}
{[2] \quad \mathrm{MRT}=\left[A_{1} /\left(A_{1}+A_{2}\right.\right.} & \left.\left.+A_{3}\right)\left(\mathrm{TD}_{1}+\tau_{1}\right)\right] \\
& +\left[A_{2} /\left(A_{1}+A_{2}+A_{3}\right)\left(\mathrm{TD}_{2}+\tau_{2}\right)\right] \\
& +\left[A_{3} /\left(A_{1}+A_{2}+A_{3}\right)\left(\mathrm{TD}_{3}+\tau_{3}\right)\right]
\end{aligned}
$$

Heart rate responses were averaged to yield a single timeseries of heart rate data for each subject at each intensity. Heart rate responses at $50 \%$ and $80 \% V_{\mathrm{T}}$ intensities were fitted using a monophasic (instead of biphasic) function according to eq. [3], as this was the model that best fitted the responses for the majority of subjects on the basis of comparing the goodness-of-fit of these 2 (monophasic and biphasic) functions (Motulsky and Ransnas 1987).

[3] Heart rate $=a+A\left[1-e^{-(t-\mathrm{TD}) / \tau}\right]$

where $a$ is the initial resting heart rate, $A$ the amplitude of the exercise response, TD the delay in rise of heart rate after exercise onset, and $\tau$ is the time constant of the response. Fitting procedures were identical to that described for $\dot{V} \mathrm{O}_{2}$.

For $50 \% \Delta$ intensities heart rate responses were fitted using a biphasic function (as described in eq. [1]) as this model was best fitted for the majority of the responses compared with a monophasic or triphasic functions (Motulsky and Ransnas 1987). The MRT for heart rate responses at $50 \% \Delta$ were calculated according to eq. [2] (using the first 2 components).

\section{SE programme}

Each subject was required to train 3 times per week normally in nonconsecutive days during the 12 -week programme. Sessions were supervised by one of the study researchers. Exercise intensities were personalised according to the incremental cycling test at BS1. Warm-up comprised 10 min of stationary cycling at $60 \%$ heart rate reserve (HRR) and static stretching of major muscle groups. Aerobic exercise comprised 35-40 min at 70\%-75\% HRR (weeks 1-6), progressing to $75 \%-80 \%$ HRR (weeks 7-12). Subjects were allowed to choose among stationary bikes, treadmills, elliptical trainers, rowers, and stair masters for aerobic exercise. Resistance training included 6 resistance exercises, 5 of which were compound exercises incorporating major muscle groups (bench press, pull down, leg press, leg extension, and squats), plus calf raises that were performed on a step whilst holding a weight. Subjects completed 1 set of 12 repetitions (weeks 1-6) at $60 \%$ of 1 repetition concentric maximum (1RM), and progressed to 2 sets of 12 repetitions (weeks $7-$ 12) at 70\% 1RM. 1RM was determined at week 0 and reassessed every 4 weeks during the programme with training loads adjusted accordingly. Cool-down comprised $5 \mathrm{~min}$ of treadmill walking and the stretching routine.

\section{UE programme}

Subjects were encouraged to train at home, at local leisure centres, or nearby facilities (parks, sports fields, etc.). A 3-month subscription in the same leisure centre where the SE was conducted was offered. All participants decided to perform all of the UE training sessions in this leisure centre. Subjects were again requested to train 3 times per week for
12 weeks and were informed of their graded test performance post-SE to assist them in personalizing the aerobic exercise component. Similar to the SE, participants were requested to begin at 30-40 $\mathrm{min}$ at $75 \%-80 \%$ HRR for aerobic exercise, and 1-2 sets of 12 repetitions at 70\% 1RM for the same 6 resistance exercises. The study investigators maintained weekly contact with subjects via phone calls and gave advice when required.

\section{Maximum strength}

Upper body (bench press) and lower body (leg extension) maximum strength were assessed (1RM) before and after the $\mathrm{SE}$ and the UE.

\section{Statistical analyses}

Physiological responses during the control period (between BS1 and BS2) were compared using a paired $t$ test. The training-related resting and peak physiological effects (between baseline, post-SE, and post-UE) were tested using 1-way repeated measures ANOVA. Cardiac responses during the constant load cycling bouts during both the control and the training period were compared using a 2-way repeated measures ANOVA (time $\times$ group). Differences were located using Tukey's post hoc test. Data that were not normally distributed were analysed using Kruskal-Wallis test and multiple comparisons were then performed using Dunn's method. The level of significance was set as $p \leq 0.05$. All values are expressed as means $\pm \mathrm{SD}$.

\section{Results}

\section{Training adherence}

Adherence to the supervised exercise program was $92 \% \pm$ $8 \%(81 \%-100 \%)$ and adherence to the unsupervised training program was $90 \% \pm 10 \%(72 \%-100 \%)$. The adherence between the 2 training programmes was not significantly different.

\section{Maximum strength (resistance training)}

Compared with baseline (i.e., pre-training), 1RM outcomes for the upper and lower body resistance exercises were significantly higher both post-SE and post-UE (bench press: $39 \pm$ $25 \mathrm{~kg}, 46 \pm 30 \mathrm{~kg}, 46 \pm 30 \mathrm{~kg}$, respectively; leg extension: $45 \pm 27 \mathrm{~kg}, 58 \pm 31 \mathrm{~kg}, 59 \pm 30 \mathrm{~kg}$, respectively), and not different between post-SE and post-UE.

\section{Physical characteristics and activity levels}

Exercise training induced significantly higher physical activity scores post-SE and post-UE compared with baseline (Table 1). There was a main significant effect on body mass $(\mathrm{kg})$ following exercise training (main effect $=$ time, $p=$ 0.048 ), although post hoc tests did not reveal significant differences between baseline and post-SE and (or) post-UE. Body mass index did not change significantly $(p=0.41)$ following SE and UE compared with baseline.

\section{Graded test}

During the control phase, peak heart rate (beats. $\mathrm{min}^{-1}$ ) was significantly lower at BS2 compared with BS1 but the rest of the variables remained unaltered (Table 2). Following the training intervention, peak $\dot{V} \mathrm{O}_{2}\left(\mathrm{~mL} \cdot \mathrm{kg}^{-1} \cdot \mathrm{min}^{-1}\right)$ and peak 
Table 1. Physical characteristics and activity levels.

\begin{tabular}{lllllc}
\hline & $\begin{array}{l}\text { BS1 } \\
(n=15)\end{array}$ & $\begin{array}{l}\text { BS2 } \\
(n=15)\end{array}$ & $\begin{array}{l}\text { Baseline } \\
(n=13)\end{array}$ & $\begin{array}{l}\text { Post-SE } \\
(n=13)\end{array}$ & $\begin{array}{l}\text { Post-UE } \\
(n=13)\end{array}$ \\
\hline Age $(\mathrm{y})$ & $50 \pm 6$ & & $51 \pm 7$ & & \\
HbA 1 c $(\%)$ & $7.3 \pm 1.2$ & & $7.1 \pm 1.2$ & & \\
FPG $\left(\mathrm{mmol} \cdot \mathrm{L}^{-1}\right)$ & $8.4 \pm 1.7$ & & $8.4 \pm 1.6$ & & \\
Body mass $(\mathrm{kg})$ & $96.9 \pm 17.1$ & $97.2 \pm 17.5$ & $93.1 \pm 18.3$ & $91.3 \pm 18.3$ & $91.6 \pm 18.1$ \\
BMI $\left(\mathrm{kg} \cdot \mathrm{m}^{-2}\right)$ & $32.8 \pm 5.8$ & $32.9 \pm 5.8$ & $31.2 \pm 3.8$ & $30.6 \pm 4.0$ & $30.6 \pm 3.9$ \\
Activity $\left(\mathrm{METs} ; \mathrm{h} \cdot \mathrm{week}^{-1}\right)$ & $160 \pm 13$ & $160 \pm 12$ & $164 \pm 13$ & $176 \pm 12^{\dagger}$ & $173 \pm 13^{\dagger}$ \\
\hline
\end{tabular}

Note: Values are means \pm SD for physical and haematological characteristics and activity levels. BS1 and BS2, baseline laboratory testing; SE, supervised exercise; UE, unsupervised exercise; FPG, fasting blood glucose; BMI, body mass index.

${ }^{\dagger}$ Significantly different $(p<0.05)$ than baseline.

Table 2. Peak physiological responses.

\begin{tabular}{|c|c|c|c|c|c|}
\hline & $\begin{array}{l}\text { BS1 } \\
(n=15)\end{array}$ & $\begin{array}{l}\mathrm{BS} 2 \\
(n=15)\end{array}$ & $\begin{array}{l}\text { Baseline } \\
(n=13)\end{array}$ & $\begin{array}{l}\text { Post-SE } \\
(n=13)\end{array}$ & $\begin{array}{l}\text { Post-UE } \\
(n=13)\end{array}$ \\
\hline Peak $\dot{V} \mathrm{O}_{2}\left(\mathrm{~mL} \cdot \mathrm{min}^{-1} \cdot \mathrm{kg}^{-1}\right)$ & $19.6 \pm 5.5$ & $20.1 \pm 4.6$ & $20.5 \pm 5.7$ & $24.9 \pm 7.4^{\dagger}$ & $24.8 \pm 8.1^{\dagger}$ \\
\hline Peak workload $(\mathrm{W})$ & $128 \pm 41$ & $127 \pm 45$ & $131 \pm 45$ & $162 \pm 61^{\dagger}$ & $165 \pm 62^{\dagger}$ \\
\hline Peak HR (beats· $\mathrm{min}^{-1}$ ) & $160 \pm 16$ & $152 \pm 14 *$ & $151 \pm 13$ & $153 \pm 14$ & $158 \pm 16$ \\
\hline Time to failure (min) & $15.4 \pm 6.1$ & $14.9 \pm 6.3$ & $15.9 \pm 6.8$ & $20.2 \pm 8.7^{\dagger}$ & $20.8 \pm 9.3^{\dagger}$ \\
\hline Workload at $V_{\mathrm{T}}(\mathrm{W})$ & $86 \pm 34$ & $86 \pm 38$ & $89 \pm 37$ & $115 \pm 65^{\dagger}$ & $132 \pm 66^{\dagger}$ \\
\hline$\dot{V} \mathrm{O}_{2}$ at $V_{\mathrm{T}}\left(\mathrm{mL} \cdot \mathrm{min}^{-1} \cdot \mathrm{kg}^{-1}\right)$ & $15.5 \pm 4.0$ & $16.1 \pm 4.5$ & $16.5 \pm 4.5$ & $19.0 \pm 6.8^{\dagger}$ & $19.5 \pm 6.6^{\dagger}$ \\
\hline
\end{tabular}

workload (W) were significantly larger post-SE and post-UE compared with baseline. Workload (W) and $\dot{V} \mathrm{O}_{2}\left(\mathrm{~mL} \cdot \mathrm{kg}^{-1} \cdot \mathrm{min}^{-1}\right)$ at $V_{\mathrm{T}}$ were also significantly larger post-SE and post-UE compared with baseline. Exercise training did not affect peak HR responses. None of the physiological responses was different between post-SE and post-UE.

\section{CO responses}

Following the training intervention, absolute values of $\mathrm{CO}$ $\left(\mathrm{L} \cdot \mathrm{min}^{-1}\right)$ were not different from baseline at any intensity (Fig. 1). However, the relative or percentage change in $\mathrm{CO}$ from rest at $30 \mathrm{~s}$ compared with $240 \mathrm{~s}$ was larger post-SE $(78 \% \pm 15 \%)$ and post-UE $(80 \% \pm 16 \%)$ compared with baseline $(64 \% \pm 16 \%)$ at $80 \% V_{\mathrm{T}}$; and tended to be larger at $50 \% V_{\mathrm{T}}(p=0.06)$ and $50 \% \Delta(p=0.14)$. HR responses at $240 \mathrm{~s}$ during all 3 cycle intensities were lower both post-SE and post-UE compared with baseline, and at $30 \mathrm{~s}$ they were reduced post-UE compared with baseline. Only at $50 \% \Delta$ was $\mathrm{HR}$ at $30 \mathrm{~s}$ lower post-SE compared with baseline. Stroke volume responses were significantly larger both at $30 \mathrm{~s}$ and $240 \mathrm{~s}$, post-SE and post-UE compared with baseline at $50 \% V_{\mathrm{T}}$, and although not significantly different, stroke volume responses tended to be larger at $80 \% V_{\mathrm{T}}(p=0.08)$ but not at $50 \% \Delta(p=0.41)$.

\section{$\dot{V} \mathrm{O}_{2}$ and $\mathrm{HR}$ kinetic responses}

The mean kinetic parameter estimates defining the biphasic $\left(50 \% V_{\mathrm{T}}\right.$ and $\left.80 \% V_{\mathrm{T}}\right)$ and triphasic $(50 \% \Delta)$ response of $\dot{V} \mathrm{O}_{2}$, as well as kinetic parameters defining the monophasic $\left(50 \% V_{\mathrm{T}}\right.$ and $\left.80 \% V_{\mathrm{T}}\right)$ and biphasic $(50 \% \Delta)$ response of $\mathrm{HR}$ during constant load cycling can be seen in Table $3 . \dot{V} \mathrm{O}_{2}$ responses during exercise at $50 \% V_{\mathrm{T}}$ in a representative individual at baseline, post-SE, and post-UE are shown in Fig. 2. Following the training intervention, the time constant of the second phase $\left(\tau_{2}\right)$ and MRT were significantly lower at all 3 intensities post-SE and post-UE compared with baseline. In addition, at the highest intensity the time constant of the third phase $\left(\tau_{3}\right)$ and $A_{3}$ were lower post-SE and post-UE compared with baseline. For the HR kinetic responses, the time constants at $50 \% V_{\mathrm{T}}$ and $80 \% V_{\mathrm{T}}$ were significantly lower post$\mathrm{SE}$ and post-UE compared with baseline. At $50 \% \Delta$, the mean response time of $\mathrm{HR}$ was lower post-SE and post-UE compared with baseline. Also, at $80 \% V_{\mathrm{T}}$ and $50 \% \Delta$, the amplitude of the HR response $\left(A_{1}\right)$ was lower post-SE and post-UE compared with baseline.

\section{Discussion}

In the present study, 12 weeks of supervised exercise training significantly increased the rate of adjustment of pulmonary $\dot{V} \mathrm{O}_{2}$ (i.e., mean response time) during 3 levels of submaximal exercise. This effect was associated with a significant and consistent reduction in the time constant of phase 2 of the $\dot{V} \mathrm{O}_{2}$ response, as well as a significant reduction in the amplitude and time constant of phase 3 at the highest intensity. Training resulted in a faster adjustment in heart rate during exercise combined with a larger relative change in $\mathrm{CO}$ over $30 \mathrm{~s}$, as well as a larger increase in stroke volume during exercise at the lowest intensity. These improvements in dynamic responses coexisted with significant increases in exercise tolerance and peak $\dot{V} \mathrm{O}_{2}$, all of which were maintained during a subsequent period of unsupervised training. 
Fig. 1. Mean $( \pm \mathrm{SD})$ cardiac output $(\mathrm{CO})$, stroke volume (SV), and heart rate (HR) during cycling exercise at $50 \%$ ventilatory threshold $\left(V_{\mathrm{T}}\right), 80 \% V_{\mathrm{T}}$ and $50 \% \Delta$ for subjects who

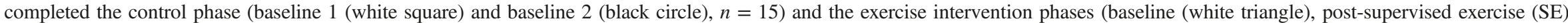
(black square) and post-unsupervised exercise (UE) (white circle), $n=13)$. *, Significantly different $(p<0.05)$ than BS1; $\dagger$, post-SE significantly different $(p<0.05)$ than baseline. $\ddagger$, post-UE significantly different $(p<0.05)$ than baseline; $\S$, post-UE significantly different $(p<0.05)$ than post-SE.
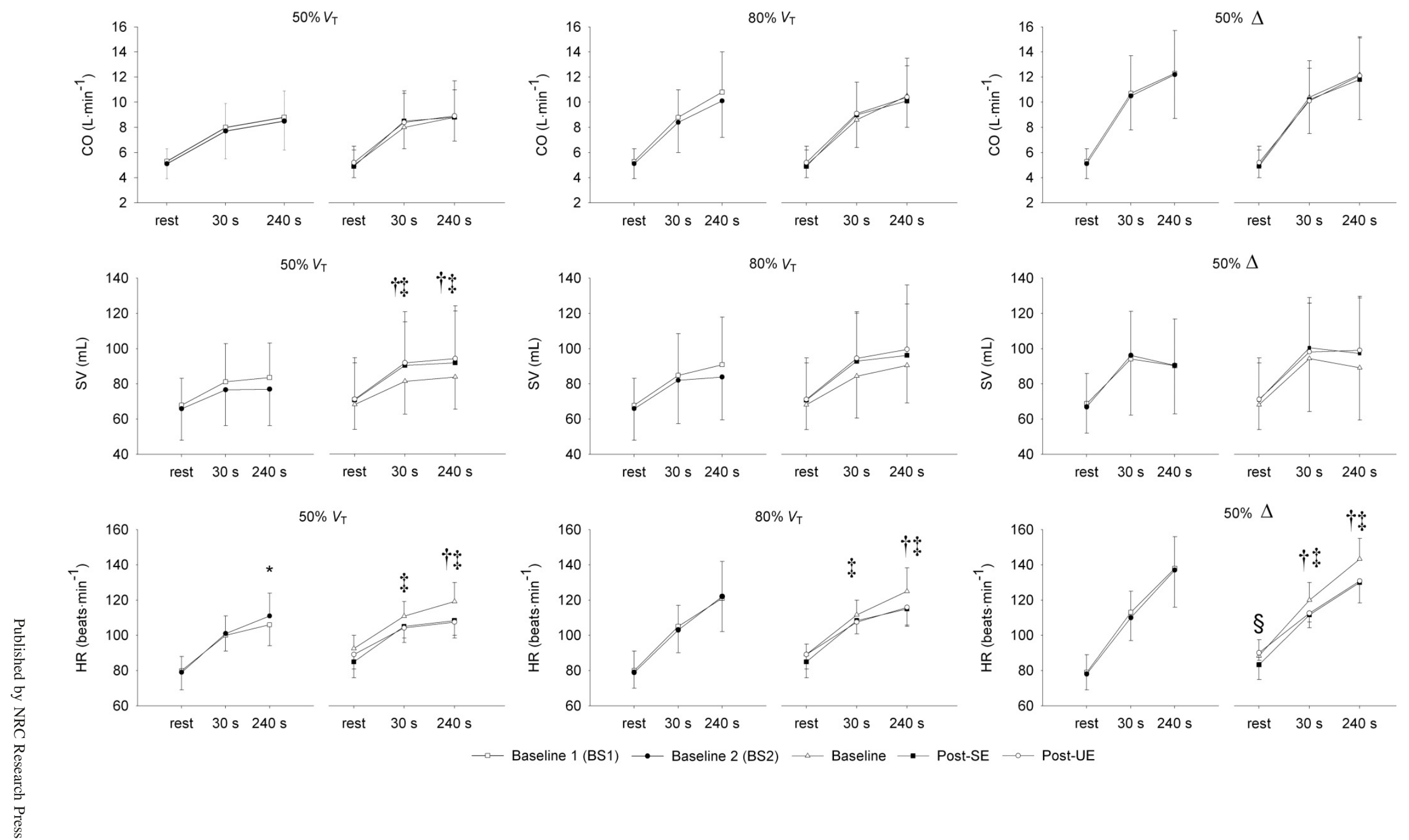
Table 3. Oxygen uptake and heart rate kinetic parameters.

\begin{tabular}{|c|c|c|c|c|c|}
\hline & $\begin{array}{l}\mathrm{BS} 1 \\
(n=15)\end{array}$ & $\begin{array}{l}\mathrm{BS} 2 \\
(n=15)\end{array}$ & $\begin{array}{l}\text { Baselines } \\
(n=13)\end{array}$ & $\begin{array}{l}\text { Post-SE } \\
(n=13)\end{array}$ & $\begin{array}{l}\text { Post-UE } \\
(n=13)\end{array}$ \\
\hline \multicolumn{6}{|l|}{$\overline{\mathbf{5 0} \% V_{\mathrm{T}}}$} \\
\hline$\dot{V} \mathrm{O}_{2} A_{1}\left(\mathrm{~L} \cdot \mathrm{min}^{-1}\right)$ & $0.35 \pm 0.11$ & $0.37 \pm 0.10$ & $0.36 \pm 0.13$ & $0.41 \pm 0.20$ & $0.43 \pm 0.13$ \\
\hline$\dot{V} \mathrm{O}_{2} \tau_{1}(\mathrm{~s})$ & $4.5 \pm 2.4$ & $5.6 \pm 2.3$ & $4.9 \pm 2.3$ & $5.3 \pm 1.7$ & $5.0 \pm 2.0$ \\
\hline$\dot{V} \mathrm{O}_{2} A_{2}\left(\mathrm{~L} \cdot \mathrm{min}^{-1}\right)$ & $0.35 \pm 0.16$ & $0.42 \pm 0.18^{*}$ & $0.43 \pm 0.19$ & $0.32 \pm 0.11^{\dagger}$ & $0.35 \pm 0.16$ \\
\hline$\dot{V} \mathrm{O}_{2} \tau_{2}(\mathrm{~s})$ & $29.2 \pm 14.0$ & $31.7 \pm 8.4$ & $29.9 \pm 10.7$ & $17.3 \pm 10.7^{\dagger}$ & $17.5 \pm 5.9^{\dagger}$ \\
\hline$\dot{V} \mathrm{O}_{2} \operatorname{MRT}(\mathrm{s})$ & $31.8 \pm 10.9$ & $37.4 \pm 8.4$ & $34.4 \pm 8.3$ & $29.7 \pm 7.4^{\dagger}$ & $25.2 \pm 4.7^{\dagger,}$ \\
\hline HR $A_{1}$ (beats. $\mathrm{min}^{-1}$ ) & $28 \pm 10$ & $23 \pm 6$ & $24 \pm 6$ & $23 \pm 3$ & $22 \pm 8$ \\
\hline $\mathrm{HR} \tau_{1}(\mathrm{~s})$ & $44.6 \pm 29.6$ & $33.0 \pm 25.0$ & $32.0 \pm 21.6$ & $10.5 \pm 4.8^{\dagger}$ & $19.3 \pm 12.1^{\dagger}$ \\
\hline \multicolumn{6}{|l|}{$80 \% V_{\mathrm{T}}$} \\
\hline$\dot{V} \mathrm{O}_{2} A_{1}\left(\mathrm{~L} \cdot \mathrm{min}^{-1}\right)$ & $0.37 \pm 0.12$ & $0.46 \pm 0.19 *$ & $0.46 \pm 0.21$ & $0.48 \pm 0.18$ & $0.54 \pm 0.21$ \\
\hline$\dot{V} \mathrm{O}_{2} \tau_{1}(\mathrm{~s})$ & $4.7 \pm 3.0$ & $5.4 \pm 3.1$ & $4.8 \pm 2.9$ & $4.2 \pm 2.5$ & $5.4 \pm 2.0$ \\
\hline$\dot{V} \mathrm{O}_{2} A_{2}\left(\mathrm{~L} \cdot \mathrm{min}^{-1}\right)$ & $0.56 \pm 0.26$ & $0.61 \pm 0.19$ & $0.61 \pm 0.23$ & $0.53 \pm 0.18$ & $0.51 \pm 0.19^{\dagger}$ \\
\hline$\dot{V} \mathrm{O}_{2} \tau_{2}(\mathrm{~s})$ & $32.4 \pm 7.9$ & $35.2 \pm 9.7$ & $34.3 \pm 12.7$ & $18.9 \pm 4.7^{\dagger}$ & $20.9 \pm 8.4^{\dagger}$ \\
\hline$\dot{V} \mathrm{O}_{2} \operatorname{MRT}(\mathrm{s})$ & $38.2 \pm 6.6$ & $40.5 \pm 10.1$ & $41.1 \pm 12.3$ & $33.4 \pm 6.1^{\dagger}$ & $32.1 \pm 6.1^{\dagger}$ \\
\hline HR $A_{1}$ (beats. $\mathrm{min}^{-1}$ ) & $39 \pm 17$ & $37 \pm 14$ & $38 \pm 11$ & $33 \pm 6^{\dagger}$ & $33 \pm 11^{\dagger}$ \\
\hline $\mathrm{HR} \tau_{1}(\mathrm{~s})$ & $47.6 \pm 19.5$ & $40.8 \pm 13.7$ & $39.6 \pm 14.1$ & $19.3 \pm 7.1^{\dagger}$ & $20.7 \pm 11.2^{\dagger}$ \\
\hline \multicolumn{6}{|l|}{$50 \% \Delta$} \\
\hline$\dot{V} \mathrm{O}_{2} A_{1}\left(\mathrm{~L} \cdot \mathrm{min}^{-1}\right)$ & $0.56 \pm 0.24$ & $0.57 \pm 0.25$ & $0.54 \pm 0.25$ & $0.58 \pm 0.22$ & $0.61 \pm 0.24$ \\
\hline$\dot{V} \mathrm{O}_{2} \tau_{1}(\mathrm{~s})$ & $6.0 \pm 3.9$ & $6.3 \pm 2.9$ & $5.6 \pm 2.4$ & $5.0 \pm 2.5$ & $4.3 \pm 2.5$ \\
\hline$\dot{V} \mathrm{O}_{2} A_{2}\left(\mathrm{~L} \cdot \mathrm{min}^{-1}\right)$ & $0.70 \pm 0.25$ & $0.80 \pm 0.33^{*}$ & $0.81 \pm 0.30$ & $0.82 \pm 0.32$ & $0.80 \pm 0.35$ \\
\hline$\dot{V} \mathrm{O}_{2} \tau_{2}(\mathrm{~s})$ & $25.6 \pm 5.7$ & $27.7 \pm 4.4$ & $27.6 \pm 3.7$ & $20.4 \pm 8.2^{\dagger}$ & $20.2 \pm 6.0^{\dagger}$ \\
\hline$\dot{V} \mathrm{O}_{2} A_{3}\left(\mathrm{~L} \cdot \mathrm{min}^{-1}\right)$ & $0.15 \pm 0.06$ & $0.14 \pm 0.07$ & $0.16 \pm 0.06$ & $0.07 \pm 0.04^{\dagger}$ & $0.09 \pm 0.05^{\dagger}$ \\
\hline$\dot{V} \mathrm{O}_{2} \tau_{3}(\mathrm{~s})$ & $107.1 \pm 49.8$ & $101.4 \pm 41.6$ & $115.4 \pm 46.1$ & $63.1 \pm 22.8^{\dagger}$ & $80.9 \pm 27.5^{\dagger}$ \\
\hline$\dot{V} \mathrm{O}_{2} \operatorname{MRT}(\mathrm{s})$ & $58.9 \pm 13.2$ & $58.6 \pm 11.5$ & $66.0 \pm 24.7$ & $48.8 \pm 15.1^{\dagger}$ & $48.5 \pm 15.2^{\dagger}$ \\
\hline HR $A_{1}$ (beats. $\mathrm{min}^{-1}$ ) & $48 \pm 13$ & $46 \pm 12$ & $51 \pm 12$ & $41 \pm 12^{\dagger}$ & $41 \pm 10^{\dagger}$ \\
\hline $\mathrm{HR} \tau_{1}(\mathrm{~s})$ & $35.7 \pm 10.9$ & $37.9 \pm 8.4$ & $37.6 \pm 9.1$ & $24.5 \pm 15.5^{\dagger}$ & $34.0 \pm 22.6$ \\
\hline HR $A_{2}$ (beats. $\min ^{-1}$ ) & $24 \pm 11$ & $16 \pm 12 *$ & $16 \pm 12$ & $11 \pm 8^{\dagger}$ & $12 \pm 8^{\dagger}$ \\
\hline $\operatorname{HR} \tau_{2}(\mathrm{~s})$ & $330.2 \pm 129.2$ & $256.1 \pm 159.4$ & $258.6 \pm 117.3$ & $116.1 \pm 146.3^{\dagger}$ & $151.2 \pm 160$ \\
\hline HR MRT (s) & $185.7 \pm 72.2$ & $133.4 \pm 22.4$ & $143.3 \pm 54.8$ & $74.4 \pm 55.6^{\dagger}$ & $92.7 \pm 57.9^{\dagger}$ \\
\hline
\end{tabular}

Note: Values are means $\pm \mathrm{SD}$ for $\dot{V} \mathrm{O}_{2}$ and HR kinetic parameters at 3 exercise intensities $\left(50 \% V_{\mathrm{T}}, 80 \% V_{\mathrm{T}}\right.$, and $\left.50 \% \Delta\right)$ for subjects who completed the control phase (BS1 and BS2) and the exercise intervention phases (baseline, post-SE, and post-UE). SE, supervised exercise; UE, unsupervised exercise; $V_{\mathrm{T}}$, ventilatory threshold; $\dot{V} \mathrm{O}_{2}$, oxygen uptake; $A_{1}, A_{2}, A_{3}$, amplitude of the exercise response for each exponential phase; $\tau_{1}, \tau_{2}, \tau_{3}$, time constant for each exponential phase; HR, heart rate; MRT, mean response time.

*Significantly different $(p<0.05)$ than BS1.

'Significantly different $(p<0.05)$ than baseline.

Significantly different $(p<0.05)$ than post-SE.

\section{Training and $\dot{V} \mathrm{O}_{2}$ kinetics}

In type 2 diabetes, exercise training is an important therapeutic modality because it improves exercise tolerance and peak $\dot{V} \mathrm{O}_{2}$ (Zanuso et al. 2010), both of which are strongly associated with cardiovascular and all-cause mortality (Wei et al. 2000; Myers et al. 2002). Although the physiological basis of these training adaptations is not clear, it might be related to an increased fatigue resistance and faster adjustment of $\dot{V} \mathrm{O}_{2}$ during submaximal exercise. The present findings reveal consistently faster $\dot{V} \mathrm{O}_{2}$ kinetics (i.e., lower MRT) across a wide range of submaximal intensities after training. These data confirm a previous report of a training-induced reduction in the time constant of pulmonary $\dot{V} \mathrm{O}_{2}$ during exercise, when the $\dot{V} \mathrm{O}_{2}$ response was assumed to be monoexponential (Brandenburg et al. 1999). However, we used a biphasic or triphasic function to characterise this response (Whipp 2009) and showed that the improved mean response time of $\dot{V} \mathrm{O}_{2}$, analogous to the finding by Brandenburg et al. (1999), was associated with a significant reduction in the time constant of phase 2 , as well as a significant reduction in the time constant and amplitude of phase 3 at the highest intensity. Since these phases of the pulmonary $\dot{V} \mathrm{O}_{2}$ response have been linked to mitochondrial control in contracting muscles (Grassi et al. 1996; Krustrup et al. 2004), then the present study suggests that exercise training in type 2 diabetes influences those $\mathrm{O}_{2}$-dependent processes that underlie phase 2 and, when it occurs at higher intensities, phase 3 of this response.

The control of $\dot{V} \mathrm{O}_{2}$ during the initial period of an acute exercise depends on the control of muscle blood flow $\left(\mathrm{O}_{2}\right.$ delivery) and $a-v \mathrm{O}_{2}$. Oxygen delivery could be linked by poor pumping capacity and (or) impaired vasodilation; whereas $a-\nu \mathrm{O}_{2}$ reflects an interaction between blood flow and oxidative metabolism. The slowed $\dot{V} \mathrm{O}_{2}$ kinetic responses in uncomplicated diabetes do not seem to be related to $\mathrm{CO}$ as its responses during submaximal cycling exercise are not slower or smaller than in nondiabetic controls (Baldi et al. 2003; MacAnaney et al. 2011a). The role of the skeletal 
Fig. 2. Representative oxygen uptake $\left(\mathrm{V}_{2}\right)$ responses during cycling exercise at intensities equivalent to $50 \% V_{\mathrm{T}}$ in an individual at baseline, post-supervised exercise, and post-unsupervised exercise. Note that at baseline, the time constant for phase $2\left(\tau_{2}\right)$ and the mean response time are slower compared with post-supervised exercise and post-unsupervised exercise. $A_{1}, A_{2}$, amplitude for phases 1 and 2 , respectively; $\tau_{1}$, $\tau_{2}$, time constant for phases 1 and 2, respectively; $\mathrm{TD}_{2}$, time delay for training phase 2 .

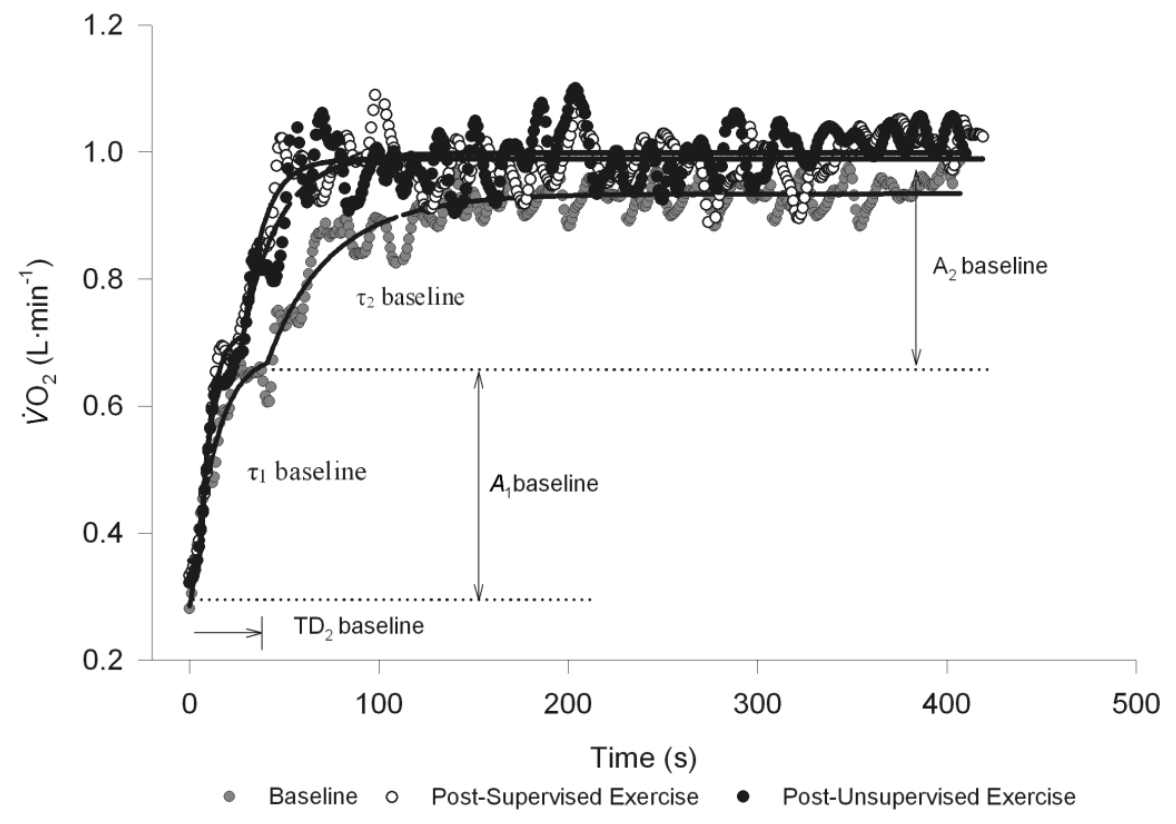

muscle is not to be excluded given the observations of a lower mitochondrial content (Ritov et al. 2005) and abnormal mitochondrial function (Kelley et al. 2002; Ritov et al. 2005; Phielix et al. 2008) in muscles of diabetics compared with healthy controls. However, $a-v \mathrm{O}_{2}$ responses during submaximal cycling adjust at a similar rate and to a similar level in type 2 diabetes compared with healthy controls (Baldi et al. 2003; MacAnaney et al. 2011a), suggesting that the capacity of $\mathrm{O}_{2}$ extraction by the diabetic skeletal muscle might not be altered during exercise. There is more evidence suggesting that the slowing of the $\dot{V} \mathrm{O}_{2}$ kinetic response in uncomplicated type 2 diabetes is linked to a maldistribution and (or) slowing of the blood flow kinetic response to the active muscle. The latter is directly supported by recent evidence of slower vascular conductance kinetic responses in diabetes than in nondiabetic controls during static calf plantar-flexion exercise (MacAnaney et al. 2011b); and similarly, the estimated microvascular blood flow responses of the quadriceps muscle has been shown to be slower during moderate cycling in subjects with type 2 diabetes compared with healthy controls (Bauer et al. 2007).

In the present study we focused on $\mathrm{O}_{2}$ delivery and, specifically, measured the relative change in $\mathrm{CO}$ over the early period of exercise $(t=30 \mathrm{~s})$ relative to its total adjustment to more stable (steady-state) levels later during submaximal exercise $(t=240 \mathrm{~s})$. Steady-state $(t=240 \mathrm{~s})$ responses of $\mathrm{CO}$ were not affected by training (Fig. 1), consistent with responses in healthy individuals (Saltin et al. 1968). Similarly, the $\mathrm{CO}$ achieved at $30 \mathrm{~s}$ was not affected by training. By contrast, the relative change in $\mathrm{CO}$ from rest to $30 \mathrm{~s}$ relative to $240 \mathrm{~s}$ was larger following training compared with baseline, demonstrating an important and novel effect of training suggestive of an enhanced dynamic response of $\mathrm{CO}$ that is independent of any effect on its amplitude.
This training induced increase in the ratio of the $\mathrm{CO}$ response at $30 \mathrm{~s}$ relative to $240 \mathrm{~s}$ coincided with a significant acceleration of the HR kinetic response (i.e., smaller $\tau$ ), a significant reduction in HR during exercise, and a larger change in stroke volume by $30 \mathrm{~s}$ of exercise. Thus, training induced a significant change in the control of both HR and stroke volume that is reasonable to assume contributed to the improved relative change in $\mathrm{CO}$ from rest at $30 \mathrm{~s}$ compared with $240 \mathrm{~s}$. Although the mechanistic basis of these cardiac effects are not clear, it is probable that underlying mechanisms relate independently to HR (e.g., vagal withdrawal) and stroke volume (e.g., increased diastolic relaxation), involve an interaction between inotropic and chronotropic mechanisms (Bolter and Wilson 1999), and (or) are influenced by the dynamic response of blood flow returning to the heart from the contracting muscles.

An implication of these findings is that the training-induced increase in $\dot{V} \mathrm{O}_{2}$ kinetics is linked causally to an increased blood flow and rate of $\mathrm{O}_{2}$ delivery to the contracting muscles. Although the training-induced increase in the ratio of the change of $\mathrm{CO}$ response from rest at $30 \mathrm{~s}$ relative to $240 \mathrm{~s}$ was manifest during exercise before a significant effect on $\dot{V} \mathrm{O}_{2}$ occurred (TD of phase $2 \cong 30 \mathrm{~s}$ ), a closer temporal alignment between these responses at the level of contracting muscles would be expected given the delay between them of $\sim 10-20 \mathrm{~s}$ that is associated with the transit of blood returning to the lungs. Consequently, even though the $\mathrm{CO}$ kinetic responses were not measured in the present study, it is tempting to suggest that the training improvement in $\dot{V} \mathrm{O}_{2}$ kinetics might be causally linked to an improved control of the dynamic response of cardiac output in type 2 diabetes.

Others have also shown significant improvements in resting left ventricular diastolic function in uncomplicated type 2 diabetes following 12 weeks of supervised aerobic exercise 
(Brassard et al. 2007); although longer training interventions seem to be required for potential alterations in left ventricular diastolic function in subjects with more advanced diabetes $\left(\mathrm{HbA}_{1 \mathrm{c}}>8 \%\right.$, Loimaala et al. (2007)). Apart from the benefits observed in cardiac (and possibly blood flow) adjustments, the improvements in $\dot{V} \mathrm{O}_{2}$ kinetic responses observed in the present study following supervised training are also likely to be mediated by adaptations in $\mathrm{O}_{2}$ extraction capacity of the active muscle. The latter is evidenced by recent work of Phielix et al. (2010), which reported increases in mitochondrial content and improvements in intrinsic mitochondrial function following 12 weeks of combined aerobic and resistance supervised training (Phielix et al. 2010). In the present study, the functional gain (i.e., the ratio between the amplitude of the $\dot{V} \mathrm{O}_{2}$ and work load obtained under different intensities) was not affected after training (results not shown) most likely because $\dot{V} \mathrm{O}_{2}$ amplitudes were not altered. On the other hand, endothelial vasodilator function has also been reported to be improved in diabetes after 8 weeks of combined aerobic and resistance supervised training (Maiorana et al. 2001 ); effects that could contribute to the speeding of $\mathrm{O}_{2}$ delivery to active muscle. To elucidate this, however, direct measurements of the dynamic responses of blood flow are required.

\section{Unsupervised training}

To our knowledge this is the first study to report that improvements in exercise tolerance, peak $\dot{V} \mathrm{O}_{2}$, and $\dot{V} \mathrm{O}_{2}$ kinetics in type 2 diabetes can be maintained through a programme of "unsupervised" exercise. Given the association between exercise tolerance and all-cause mortality (Myers et al. 2002), these findings support the efficacy of unsupervised exercise training in the treatment of type 2 diabetes and its complications, at least in the short-term. Participants in the present study chose to perform unsupervised exercise in a "leisure centre", and although the level of support and supervision was much less than that which was part of supervised training, we acknowledge that some level of "supervision" and support from centre staff would have occurred. Nevertheless, the incorporation of less supervised training in such environments into a programme with an initial phase of intense supervision represents a potentially effective way of educating and motivating participants to exercise on their own and ensure long-term exercise adherence. In the present study, adherence to the unsupervised training was high and similar to that for supervised training, and this good outcome of unsupervised exercise might be related to exercise being conducted in the same health centre previously used for the supervised training, and participants being familiar with the training routines and equipment used.

\section{Limitations}

Despite the lack of a control group, the design of the present study included 2 complete and identical baseline measurements separated by a long baseline period (12 weeks) and demonstrated stability in measurements before the training period. In addition, the effect of supervised training persisted when this training was changed to what might be argued to be a less effective training. The stability in measurements within the baseline period was evident by the similar peak physiological responses during the graded test, and similar $\dot{V} \mathrm{O}_{2}$ and $\mathrm{HR}$ kinetic response time constants and time delays at the 3 submaximal cycling intensities. The study design was required because it was very difficult to recruit more than 19 normotensive patients with recently diagnosed type 2 diabetes who were willing to take part in this long intervention study. Due to the limited temporal resolution of the inert gas rebreathing technique, $\mathrm{CO}$ was not assessed continuously, and as discussed, we were only able to estimate the training-induced percentage change in $\mathrm{CO}$ from rest at $30 \mathrm{~s}$ compared with $240 \mathrm{~s}$. Further work examining $\mathrm{CO}$ responses more frequently is warranted to better elucidate if training effects the dynamic response of $\mathrm{CO}$ in type 2 diabetes.

In conclusion, type 2 diabetes slows the adjustment of $\dot{V} \mathrm{O}_{2}$ at the beginning of light to moderate exercise, and as a consequence, uncomplicated diabetic subjects perceive daily light routine activities as being more difficult (Huebschmann et al. 2009). The present findings confirm that a supervised exercise programme results in the speeding of the $\dot{V} \mathrm{O}_{2} \mathrm{ki}$ netic responses and that these benefits can be maintained with a follow-up gymnasium-based unsupervised programme. Faster adjustments in $\dot{V} \mathrm{O}_{2}$ are related to improvements in exercise tolerance that might help to increase the willingness to adopt a more active lifestyle and increase the quality of life in subjects with diabetes.

\section{References}

Amann, M., Subudhi, A., and Foster, C. 2004. Influence of testing protocol on ventilatory thresholds and cycling performance. Med. Sci. Sports Exerc. 36(4): 613-622. doi:10.1249/01.MSS. 0000122076.21804.10. PMID:15064589.

Baldi, J.C., Aoina, J.L., Oxenham, H.C., Bagg, W., and Doughty, R.N. 2003. Reduced exercise arteriovenous $\mathrm{O} 2$ difference in Type 2 diabetes. J. Appl. Physiol. 94(3): 1033-1038. PMID:12571134.

Barstow, T.J., Jones, A.M., Nguyen, P.H., and Casaburi, R. 1996. Influence of muscle fiber type and pedal frequency on oxygen uptake kinetics of heavy exercise. J. Appl. Physiol. 81(4): 1642 1650. PMID:8904581.

Bauer, T.A., Reusch, J.E., Levi, M., and Regensteiner, J.G. 2007. Skeletal muscle deoxygenation after the onset of moderate exercise suggests slowed microvascular blood flow kinetics in type 2 diabetes. Diabetes Care, 30(11): 2880-2885. doi:10.2337/dc070843. PMID: 17675540.

Beaver, W.L., Wasserman, K., and Whipp, B.J. 1986. A new method for detecting anaerobic threshold by gas exchange. J. Appl. Physiol. 60(6): 2020-2027. PMID:3087938.

Bolter, C.P., and Wilson, S.J. 1999. Influence of right atrial pressure on the cardiac pacemaker response to vagal stimulation. Am. J. Physiol. 276(4): R1112-R1117. PMID:10198392.

Brandenburg, S.L., Reusch, J.E., Bauer, T.A., Jeffers, B.W., Hiatt, W.R., and Regensteiner, J.G. 1999. Effects of exercise training on oxygen uptake kinetic responses in women with type 2 diabetes. Diabetes Care, 22(10): 1640-1646. doi:10.2337/diacare.22.10. 1640. PMID: 10526728.

Brassard, P., Legault, S., Garneau, C., Bogaty, P., Dumesnil, J.G., and Poirier, P. 2007. Normalization of diastolic dysfunction in type 2 diabetics after exercise training. Med. Sci. Sports Exerc. 39(11): 1896-1901. doi:10.1249/mss.0b013e318145b642. PMID: 17986895.

Burnley, M., Doust, J.H., and Jones, A.M. 2006. Time required for the restoration of normal heavy exercise VO2 kinetics following 
prior heavy exercise. J. Appl. Physiol. 101(5): 1320-1327. doi:10. 1152/japplphysiol.00475.2006. PMID:16857864.

Dunstan, D.W., Daly, R.M., Owen, N., Jolley, D., Vulikh, E., Shaw, J., and Zimmet, P. 2005. Home-based resistance training is not sufficient to maintain improved glycemic control following supervised training in older individuals with type 2 diabetes. Diabetes Care, 28(1): 3-9. doi:10.2337/diacare.28.1.3. PMID: 15616225.

Grassi, B., Poole, D.C., Richardson, R.S., Knight, D.R., Erickson, B.K., and Wagner, P.D. 1996. Muscle O2 uptake kinetics in humans: implications for metabolic control. J. Appl. Physiol. 80(3): 988998. PMID:8964765.

Huebschmann, A.G., Reis, E.N., Emsermann, C., Dickinson, L.M., Reusch, J.E., Bauer, T.A., and Regensteiner, J.G. 2009. Women with type 2 diabetes perceive harder effort during exercise than nondiabetic women. Appl. Physiol. Nutr. Metab. 34(5): 851-857. doi:10.1139/H09-074. PMID:19935846.

Hughson, R.L., and Tschakovsky, M.E. 1999. Cardiovascular dynamics at the onset of exercise. Med. Sci. Sports Exerc. 31(7): 1005-1010. doi:10.1097/00005768-199907000-00013. PMID: 10416562.

Jakovljevic, D.G., Nunan, D., Donovan, G., Hodges, L.D., Sandercock, G.R., and Brodie, D.A. 2008. Comparison of cardiac output determined by different rebreathing methods at rest and at peak exercise. Eur. J. Appl. Physiol. 102(5): 593-599. doi:10.1007/ s00421-007-0631-4. PMID:18074146.

Kelley, D.E., He, J., Menshikova, E.V., and Ritov, V.B. 2002. Dysfunction of mitochondria in human skeletal muscle in type 2 diabetes. Diabetes, 51(10): 2944-2950. doi:10.2337/diabetes.51. 10.2944. PMID: 12351431 .

Kingwell, B.A., Formosa, M., Muhlmann, M., Bradley, S.J., and McConell, G.K. 2003. Type 2 diabetic individuals have impaired leg blood flow responses to exercise: role of endotheliumdependent vasodilation. Diabetes Care, 26(3): 899-904. doi:10. 2337/diacare.26.3.899. PMID:12610056.

Kjaer, M., Hollenbeck, C.B., Frey-Hewitt, B., Galbo, H., Haskell, W., and Reaven, G.M. 1990. Glucoregulation and hormonal responses to maximal exercise in non-insulin-dependent diabetes. J. Appl. Physiol. 68(5): 2067-2074. PMID:2193907.

Kriska, A.M., Edelstein, S.L., Hamman, R.F., Otto, A., Bray, G.A., Mayer-Davis, E.J., et al. 2006. Physical activity in individuals at risk for diabetes: Diabetes Prevention Program. Med. Sci. Sports Exerc. 38(5): 826-832. doi:10.1249/01.mss.0000218138.91812. f9. PMID: 16672833.

Krustrup, P., Söderlund, K., Mohr, M., and Bangsbo, J. 2004. The slow component of oxygen uptake during intense, sub-maximal exercise in man is associated with additional fibre recruitment. Pflugers Arch. 447(6): 855-866. doi:10.1007/s00424-003-1203-z. PMID:14758477.

Lalande, S., Gusso, S., Hofman, P.L., and Baldi, J.C. 2008. Reduced leg blood flow during submaximal exercise in type 2 diabetes. Med. Sci. Sports Exerc. 40(4): 612-617. doi:10.1249/MSS. 0b013e318161aa99. PMID:18317387.

Loimaala, A., Groundstroem, K., Rinne, M., Nenonen, A., Huhtala, H., and Vuori, I. 2007. Exercise training does not improve myocardial diastolic tissue velocities in Type 2 diabetes. Cardiovasc. Ultrasound, 5(1): 32. doi:10.1186/1476-7120-5-32. PMID:17897465.

MacAnaney, O., Malone, J., Warmington, S., O’Shea, D., Green, S., and Egaña, M. 2011a. Cardiac output is not related to the slowed $\mathrm{O}_{2}$ uptake kinetics in type 2 diabetes. Med. Sci. Sports Exerc. 43(6): 935-942. doi:10.1249/MSS.0b013e3182061cdb. PMID: 21131874.

MacAnaney, O., Reilly, H., O’Shea, D., Egaña, M., and Green, S. 2011b. Effect of type 2 diabetes on the dynamic response characteristics of leg vascular conductance during exercise. Diab. Vasc. Dis. Res. 8(1): 12-21. doi:10.1177/1479164110389625. PMID:21262866.

MacDonald, M.J., Shoemaker, J.K., Tschakovsky, M.E., and Hughson, R.L. 1998. Alveolar oxygen uptake and femoral artery blood flow dynamics in upright and supine leg exercise in humans. J. Appl. Physiol. 85(5): 1622-1628. PMID:9804561.

Maiorana, A., O'Driscoll, G., Cheetham, C., Dembo, L., Stanton, K., Goodman, C., et al. 2001. The effect of combined aerobic and resistance exercise training on vascular function in type 2 diabetes. J. Am. Coll. Cardiol. 38(3): 860-866. doi:10.1016/S0735-1097 (01)01439-5. PMID:11527646.

Motulsky, H.J., and Ransnas, L.A. 1987. Fitting curves to data using nonlinear regression: a practical and nonmathematical review. FASEB J. 1(5): 365-374. PMID:3315805.

Myers, J., Prakash, M., Froelicher, V., Do, D., Partington, S., and Atwood, J.E. 2002. Exercise capacity and mortality among men referred for exercise testing. N. Engl. J. Med. 346(11): 793-801. doi:10.1056/NEJMoa011858. PMID:11893790.

Padilla, D.J., McDonough, P., Behnke, B.J., Kano, Y., Hageman, K.S., Musch, T.I., and Poole, D.C. 2006. Effects of Type II diabetes on capillary hemodynamics in skeletal muscle. Am. J. Physiol. Heart Circ. Physiol. 291(5): H2439-H2444. doi:10.1152/ ajpheart.00290.2006. PMID:16844923.

Padilla, D.J., McDonough, P., Behnke, B.J., Kano, Y., Hageman, K.S., Musch, T.I., and Poole, D.C. 2007. Effects of Type II diabetes on muscle microvascular oxygen pressures. Respir. Physiol. Neurobiol. 156(2): 187-195. doi:10.1016/j.resp.2006.08.008. PMID:17015044.

Phielix, E., Schrauwen-Hinderling, V.B., Mensink, M., Lenaers, E., Meex, R., Hoeks, J., et al. 2008. Lower intrinsic ADP-stimulated mitochondrial respiration underlies in vivo mitochondrial dysfunction in muscle of male type 2 diabetic patients. Diabetes, 57(11): 2943-2949. doi:10.2337/db08-0391. PMID:18678616.

Phielix, E., Meex, R., Moonen-Kornips, E., Hesselink, M.K., and Schrauwen, P. 2010. Exercise training increases mitochondrial content and ex vivo mitochondrial function similarly in patients with type 2 diabetes and in control individuals. Diabetologia, 53(8): 1714-1721. doi:10.1007/s00125-010-1764-2. PMID:20422397.

Poole, D.C., Barstow, T.J., McDonough, P., and Jones, A.M. 2008. Control of oxygen uptake during exercise. Med. Sci. Sports Exerc. 40(3): 462-474. doi:10.1249/MSS.0b013e31815ef29b. PMID: 18379208.

Regensteiner, J.G., Sippel, J., McFarling, E.T., Wolfel, E.E., and Hiatt, W.R. 1995. Effects of non-insulin-dependent diabetes on oxygen consumption during treadmill exercise. Med. Sci. Sports Exerc. 27(6): 875-881. PMID:7658949.

Regensteiner, J.G., Bauer, T.A., Reusch, J.E., Brandenburg, S.L., Sippel, J.M., Vogelsong, A.M., et al. 1998. Abnormal oxygen uptake kinetic responses in women with type II diabetes mellitus. J. Appl. Physiol. 85(1): 310-317. PMID:9655791.

Regensteiner, J.G., Bauer, T.A., Reusch, J.E., Quaife, R.A., Chen, M.Y., Smith, S.C., et al. 2009. Cardiac dysfunction during exercise in uncomplicated type 2 diabetes. Med. Sci. Sports Exerc. 41(5): 977-984. doi:10.1249/MSS.0b013e3181942051. PMID: 19346991.

Ritov, V.B., Menshikova, E.V., He, J., Ferrell, R.E., Goodpaster, B.H., and Kelley, D.E. 2005. Deficiency of subsarcolemmal mitochondria in obesity and type 2 diabetes. Diabetes, 54(1): 8-14. doi:10.2337/diabetes.54.1.8. PMID:15616005.

Saltin, B., Blomqvist, G., Mitchell, J.H., Johnson, R.L., Jr, Wildenthal, K., and Chapman, C.B. 1968. Response to exercise after 
bed rest and after training. Circulation, 38(5 Suppl.): VII1-VII78. PMID:5696236.

Timmons, J.A., Poucher, S.M., Constantin-Teodosiu, D., Worrall, V., MacDonald, I.A., and Greenhaff, P.L. 1996. Metabolic responses of canine gracilis muscle during contraction with partial ischemia. Am. J. Physiol. 270(3): E400-E406. PMID:8638684.

Wei, M., Gibbons, L.W., Kampert, J.B., Nichaman, M.Z., and Blair, S.N. 2000. Low cardiorespiratory fitness and physical inactivity as predictors of mortality in men with type 2 diabetes. Ann. Intern. Med. 132(8): 605-611. PMID:10766678.

Whipp, B.J. 2009. Point: the kinetics of oxygen uptake during muscular exercise do manifest time-delayed phases. J. Appl.
Physiol. 107(5): 1663-1665. doi:10.1152/japplphysiol.00158. 2009. PMID:19228993.

Wilkerson, D.P., Poole, D.C., Jones, A.M., Fulford, J., Mawson, D.M., Ball, C.I., and Shore, A.C. 2011. Older type 2 diabetic males do not exhibit abnormal pulmonary oxygen uptake and muscle oxygen utilization dynamics during submaximal cycling exercise. Am. J. Physiol. Regul. Integr. Comp. Physiol. 300(3): R685-R692. doi:10.1152/ajpregu.00479.2010. PMID:21178129.

Zanuso, S., Jimenez, A., Pugliese, G., Corigliano, G., and Balducci, S. 2010. Exercise for the management of type 2 diabetes: a review of the evidence. Acta Diabetol. 47(1): 15-22. doi:10.1007/s00592009-0126-3. PMID:19495557. 
Copyright of Applied Physiology, Nutrition \& Metabolism is the property of Canadian Science Publishing and its content may not be copied or emailed to multiple sites or posted to a listserv without the copyright holder's express written permission. However, users may print, download, or email articles for individual use. 